\title{
Expectativas Racionais e Eficiência Informacional: Análise do Mercado Acionário Brasileiro no Período 1997-1999
}

\author{
Fernanda F. Cordeiro Perobelli \\ Fernando S. Perobelli \\ Marcelo Aarestrup Arbex
}

\begin{abstract}
RESUMO
O objetivo do artigo é testar a eficiência do mercado acionário brasileiro em relação à condução de política monetária. No período compreendido entre a crise asiática e a flexibilização do câmbio, os agentes souberam avaliar corretamente as informações disponíveis e formar expectativas acerca da conduta do Governo, mesmo em momentos de crise, para a manutenção da política de regras vigente. $\mathrm{O}$ referencial teórico baseia-se na literatura de expectativas racionais e em suas relações com o conceito de eficiência informacional dos mercados. Como proxy do comportamento do mercado brasileiro foi utilizado o índice da Bolsa de Valores de São Paulo (IBOVESPA), cuja variação pode ser entendida como a taxa de retorno neste mercado. Para a avaliação do comportamento dos retornos foi utilizado o teste de postos de Wilcoxon, a partir do qual foi possível inferir que o mercado de capitais brasileiro se mostrou eficiente em relação à condução de política econômica num cenário de regras.
\end{abstract}

Palavras-chaves: expectativas racionais; regras de política econômica; eficiência informacional; IBOVESPA.

\begin{abstract}
The purpose of this paper is to test the Brazilian capital market's efficiency in face of monetary policy. In the period between the Asian crisis and the exchange flexibilization, the agents made a correct use of the available information and formed expectations about the policymaker's behavior, even in the moments of crisis, in order to maintain the political rules adopted previously. The study's approach was based on the discussion about rational expectations and their relationship with efficient markets. The Bolsa de Valores de São Paulo index (IBOVESPA) was chosen as a proxy to Brazilian capital market's behavior, because the index variation can be understood as the rate of return in that market. To evaluate the return's behavior, the Wilcoxon ranks test was employed. From this statistical test's results, it was possible to infer that the Brazilian market was efficient in face of the behavior of economic policy by rules.
\end{abstract}

Key words: rational expectations; rules; efficient markets; IBOVESPA. 


\section{INTRODUÇÃO}

As turbulências enfrentadas pela economia brasileira nos últimos anos refletem o fato de que o país ainda não alcançou a estabilidade econômica. Apesar da origem externa dos choques e reconhecendo os ganhos expressivos no que se refere à redução da inflação e a avanços em diversas áreas, compreendendo tanto ações de caráter regulatório quanto institucional, é importante afirmar que, do ponto de vista dos fundamentos macroeconômicos, faz-se necessária a promoção de ajustes.

A estabilização decorre da identificação das causas passadas de inflação, tais como a participação excessiva do Estado nas atividades econômicas, o elevado grau de fechamento da economia e o desequilíbrio financeiro e estrutural do setor público. Cabe ressaltar que a estabilização é condição necessária, mas não suficiente, para o processo de mudança estrutural: possibilita o alargamento do horizonte de planejamento e diminui as incertezas, mas por si só não é capaz de promover o crescimento econômico. Nos últimos anos, juntamente com taxas inflacionárias reduzidas, o país apresentou taxas de crescimento econômico declinantes e taxas de juros reais em patamares elevados, provocando maior endividamento dos setores público e privado, bem como o aumento do desemprego.

A estabilidade econômica e a confiança dos agentes econômicos na capacidade do Governo de comprometer-se com uma regra de política econômica têm reflexos diretos sobre o mercado financeiro brasileiro. Dada a sua estrutura e dinamismo, esse setor da economia consegue captar, de forma relativamente rápida, as expectativas dos agentes econômicos com relação à condução e aos resultados das políticas econômicas governamentais.

Além disso, destaca-se que, com a maior integração dos mercados financeiros internacionais, políticas macroeconômicas sólidas e consistentes são fundamentais para atrair investidores para o mercado nacional de capitais. A globalização financeira impõe que os governos formulem e conduzam políticas econômicas críveis e transparentes, tanto para os agentes privados internos quanto externos.

Segundo Bekaert et al.(1995), taxas inflacionárias altas e flutuantes geram incerteza no cenário econômico. Isso dificulta o planejamento do investimento, redistribui arbitrariamente a renda, levando a taxas de retorno reais negativas e exaurindo a poupança. Nesse sentido, existe um consenso de que os governos exercem papel significativo para a eficiência do mercado financeiro, quando adotam políticas não inflacionárias confiáveis, sendo uma das tarefas essenciais do Governo, segundo ressaltam os autores, prover um ambiente macroeconômico estável. 
O Plano Real, implementado em julho de 1994, tinha como objetivo principal a estabilização de preços. A política macroeconômica, a partir de então, foi conduzida sob regras - ou seja, anúncio e comprometimento por parte dos policymakers com uma meta de inflação próxima a zero - e não discricionariamente; portanto, nesse cenário, torna-se relevante observar o comportamento do mercado acionário brasileiro ante dois choques externos (crise asiática e crise russa) e dois rearranjos de conduta internos (acordo com o Fundo Monetário Internacional e flexibilização do câmbio).

O objetivo deste trabalho é testar a hipótese de que o mercado acionário brasileiro, ao não promover ajustes bruscos no patamar dos retornos durante a crise asiática, a moratória russa e o acordo com o Fundo Monetário Internacional (FMI), mas agindo de forma oposta quando da flexibilização do câmbio, é eficiente em relação à condução da política monetária, ou seja, soube avaliar corretamente as informações disponíveis e formar expectativas na direção de que o Governo trabalharia, mesmo em momentos de crise, para a manutenção da política de regras vigente.

O artigo, além desta parte introdutória, em sua segunda seção, discute a conduta de política macroeconômica e o papel das expectativas, assim como a eficiência informacional dos mercados; em sua terceira seção, apresenta o método e o teste de hipótese utilizado e descreve o período de análise; na quarta seção, discute os resultados e na quinta são apresentadas as conclusões.

\section{Referencial Té́rico}

\section{Expectativas Racionais e Condução de Política Macroeconômica}

A condução apropriada dos instrumentos de política econômica, como a política monetária, fiscal e cambial, é identificada como o elemento crucial para se alcançar a estabilidade econômica. Historicamente, uma controvérsia sobre a conduta apropriada da política monetária arraigou-se na literatura econômica, tornando-se conhecida como o debate regras versus discricionariedade em política monetária, apresentando duas proposições polares. De um lado, os monetaristas, proponentes da adoção de regras na conduta da política monetária, na ciência de que grande parte da instabilidade ocorrida nas economias ocidentais era devida à conduta inapropriada da política monetária, ou seja, ao excesso de discricionariedade. Do lado oposto, os não monetaristas, que acreditam na potencialidade e virtude de uma política monetária discricionária, a qual permitiria a perseguição de uma política monetária ótima, do tipo sintonia fina (Silva Jr., 1996). 
A revolução das expectativas racionais da década de 70 mostrou que as expectativas influenciam sobremaneira os resultados das políticas econômicas, ao enfatizar que as expectativas do público são formadas em função de todas as informações disponíveis, incluindo as informações de possíveis atitudes futuras do Governo. Dessa forma, qualquer decisão sobre a implementação de determinada política econômica deveria levar em conta o impacto das expectativas acerca dessa política nos seus resultados posteriores.

Segundo Muth (1992), desde que as expectativas são predições informadas de eventos futuros, elas são essencialmente as mesmas predições da teoria econômica relevante. Acrescenta-se ainda que os agentes econômicos geralmente não perdem informações e que as expectativas dependem especificamente da estrutura do sistema econômico como um todo. De forma complementar, Sargent e Wallace (1992) afirmam que as expectativas sobre uma variável são ditas racionais, se elas dependem, de modo estrito, das mesmas coisas que a teoria econômica diz atualmente determinar esta variável.

Segundo Begg (1982), a idéia de expectativas racionais está concernente com a idéia de incentivos para adquirir informações e a exploração das oportunidades de lucro pela revisão do comportamento por parte dos agentes econômicos. Para o autor, a hipótese aborda a noção de que passados são passados, ou seja, os agentes não devem persistir em erros sistemáticos. Isto não implica, entretanto, que os agentes invariavelmente planejam com perfeição em um mundo em que alguns movimentos aleatórios são inevitáveis. Assim, a hipótese de expectativas racionais tem como proposição que as estimativas sobre o futuro devem ser corretas, em média, se os agentes se mantêm satisfeitos com seus mecanismos de formação de expectativas.

De acordo com Lucas Jr. e Sargent (1996), um agente sábio usaria valores passados e correntes de muitas variáveis endógenas e exógenas no modelo, tendo em vista a formação de expectativas sobre alguma variável. Dewbre (1981) afirma que, para algum ponto dado no tempo, as variáveis futuras refletem toda a informação publicamente disponível e mudanças observadas nas variáveis correntes e futuras através do tempo são decorrência exclusiva de mudanças não antecipadas pelos agentes ${ }^{(1)}$.

No contexto da teoria de expectativas racionais, a preocupação com os resultados das políticas econômicas levou à análise das reações do setor privado às medidas e decisões governamentais. A característica principal dessa literatura é a de que o público, interagindo estrategicamente com a autoridade econômica, determinaria o seu comportamento com base em suas expectativas sobre o provável curso das políticas correntes e futuras (Persson e Tabellini, 1996). 
De acordo com Arbex, Almeida e Fontes (1997), o policymaker é tipicamente um agente racional e maximizador, que responde a incentivos e restrições, da mesma forma que o resto da economia. A teoria da política econômica, que negligencia esses incentivos na formulação da política, é incompleta e limita a capacidade de prescrições. De acordo com Persson e Tabellini (1996), num nível abstrato, a nova abordagem pode ser descrita como a análise do problema públicopolicymaker ou, em outras palavras, como a análise do jogo entre público e policymaker.

Nesse sentido, a implementação de uma política econômica é um jogo entre o Governo e os agentes privados, os quais têm expectativas e, portanto, reagem às ações tomadas pelos policymakers. Levando-se em consideração que as decisões correntes dos agentes econômicos dependem em parte de suas expectativas a respeito das políticas futuras e que o Governo desconsidera tais efeitos, as políticas econômicas discricionárias podem ter um resultado até inverso ao pretendido, havendo, então, a possibilidade de que políticas consistentes comportem otimização decrescente, ex-post.

Assim sendo, Kydland e Prescott (1977) sugerem a adoção de políticas de regras como forma de reduzir a inconsistência temporal de seus planos ótimos ${ }^{(2)}$. Nesse mesmo contexto, Calvo (1978) observa que as economias em que os indivíduos são sensíveis aos anúncios de políticas futuras têm, em princípio, as sementes da inconsistência temporal. Como o autor observa, o problema de inconsistência temporal não é conseqüência direta da desarmonia entre os objetivos do Governo e as expectativas do público, podendo ocorrer mesmo quando o policymaker procura maximizar o bem-estar de um indivíduo representativo.

De acordo com Kantor (1979), com políticas de estabilização ou sem elas, a economia e os agentes econômicos são vulneráveis à incerteza ou, para usar a terminologia de expectativas racionais, a choques aleatórios. Os choques podem ser reais ou nominais, temporários ou permanentes. Choques têm efeitos reais exatamente porque eles não são e não podem ser antecipados. Para realizar planos apropriados, os agentes econômicos têm de identificar a natureza e a duração dos choques. Políticas de estabilização discricionárias, as quais privilegiam choques nominais sobre os reais, não devem ser apropriadas.

Buiter (1980), citado por Barbosa (1992), afirma que o Governo não pode introduzir surpresas sistemáticas na economia, quando a parte determinística do comportamento do Governo é incluída no conjunto de informações que condicionam as previsões privadas. As variáveis futuras antecipadas no tempo t são esperanças matemáticas verdadeiras das variáveis futuras condicionais para todas as variáveis do modelo que são conhecidas do público no tempo t. 
As expectativas racionais, quando aplicadas no contexto de modelos econômicos, são a hipótese de que as expectativas são as predições implicadas no próprio modelo, contingente à informação que os agentes econômicos se presume tenham. Em particular, se os agentes econômicos são considerados conhecedores da regra de política que está sendo seguida pela autoridade monetária, essa própria regra afetará as expectativas (Fisher, 1977).

Enfim, é possível concluir que, num ambiente no qual os agentes são racionais e se utilizam de todas as informações disponíveis para realizar suas previsões, a condução da política econômica tem grande relevância na formação de expectativas pelos agentes econômicos.

\section{Eficiência Informacional dos Mercados}

O preço de uma ação representa o equilíbrio entre as forças de oferta e demanda no mercado acionário. Os preços das ações são, ainda, indicadores das expectativas futuras dos agentes com relação à lucratividade e desempenho de uma determinada empresa, na medida em que os agentes se valem das informações disponíveis para a formação desses preços. O processo contínuo de acúmulo de informações por parte dos indivíduos faz com que eles não persistam em erros sistemáticos. Nesse sentido, os agentes revisam suas expectativas à medida que novas informações são incorporadas ao seu conjunto inicial.

A hipótese de eficiência de mercado pressupõe que mudanças nos preços devem ser originadas por processos aleatórios, que conduzam ao uso eficiente de um dado conjunto de informações na previsão do comportamento futuro de tais preços. Segundo Fama (1970), um mercado em que os preços dos ativos sempre refletem completamente toda a informação disponível é dito eficiente. Neste mercado, os preços são um sinal acurado do verdadeiro valor dos ativos e os seus retornos devem apresentar independência serial, ou seja, as mudanças dos preços devem ser linearmente independentes.

Assim, a hipótese de eficiência de mercados pressupõe que não deva existir nenhum padrão sistemático de comportamento para as mudanças dos preços (ou retornos). Se houvesse algum padrão recorrente de qualquer tipo, os agentes poderiam reconhecê-lo e usá-lo para prever o comportamento futuro deles. Com isso, estaria aberto o caminho para a existência de lucro supernormal por parte daqueles que melhor soubessem identificar e aproveitar tais regularidades; no entanto, em mercados eficientes, a simples tentativa de usar tais padrões sistemáticos faria com que eles fossem eliminados.

A hipótese de eficiência de mercados apresenta duas implicações: (1) as expectativas são racionais, na medida em que os indivíduos evitam cometer erros de 
previsão, dado um conjunto de informações e (2) qualquer discrepância entre as taxas de retorno esperadas das ações é rapidamente arbitrada, eliminando assim potenciais lucros supernormais. Dado um conjunto de informações coletado em intervalos discretos, a hipótese de mercados eficientes assume que o processo de arbitragem já tenha ocorrido ao longo do período. Essa observação permite analisar a implicação das informações disponíveis, completamente refletidas nos preços coletados, sem que seja necessário modelar o processo de arbitragem.

De acordo com Begg (1982), pode admitir-se que o mercado se equilibre continuamente e que o preço de equilíbrio, $\mathrm{p}_{\mathrm{t}}$, de uma ação dependa do seu retorno esperado. Por sua vez, esse retorno possui dois componentes: (1) dividendos pagos durante o período e (2) ganho ou perda de capital entre este período e uma data futura. É conveniente supor que os dividendos recebidos são utilizados na compra de mais papéis e que $\mathrm{p}_{\mathrm{t}+1}$ denota o valor, no tempo $\mathrm{t}+1$, do ativo original acrescido dos dividendos recebidos ao longo do período. Define-se, então, o retorno esperado para um período $\left(\delta_{t} \delta_{t+1}\right)$ por:

$$
{ }_{t} p^{e}{ }_{t+1}=\left(1+\delta_{t} e_{t+1}\right) p_{t}
$$

Assume-se que as expectativas subjetivas ${ }_{t} \mathrm{p}_{t+1}^{\mathrm{e}}{ }_{t}{ }_{t} \delta_{t+1}^{\mathrm{e}}$ satisfazem a hipótese de expectativas racionas, dadas as informações no tempo t.

Para completar o modelo é necessária uma teoria da taxa de retorno esperada de equilíbrio para cada ação. Esta questão é abordada pela teoria de portfólio baseada em Markowitz (1959), citado por Begg (1982), a qual afirma que a desejabilidade de diferentes ativos não pode ser descrita apenas em termos de seus retornos esperados. Indivíduos avessos ao risco preocupam-se também com a variabilidade, ou risco ex-post, de seus portfólios. Assim, considere que a taxa esperada de retorno assuma um valor constante $(\delta)$. Dado que o valor atual da ação, $\mathrm{p}_{\mathrm{t}+1}$, difere de seu valor esperado, $\mathrm{p}_{\mathrm{t}+1}^{\mathrm{e}}$, apenas por um erro de previsão, $\eta_{t+1}$, o qual é serialmente não-correlacionado e tem média zero, a evolução dos preços das ações pode ser representada por $^{(3)}$ :

$$
\mathrm{p}_{\mathrm{t}+1}={ }_{\mathrm{t}} \mathrm{p}_{\mathrm{t}+1}^{\mathrm{e}}+\eta_{\mathrm{t}+1}=(1+\delta) \mathrm{p}_{\mathrm{t}}+\eta_{\mathrm{t}+1}
$$

Esse modelo de previsão naive é o chamado processo de martingale. Tal modelo postula que a melhor estimativa do preço da ação um período à frente, dado o conjunto de informações passadas, é o próprio preço corrente. Se o mercado é eficiente, qualquer informação que gere uma expectativa de preço maior no futuro deve imediatamente elevar o preço corrente, de forma a eliminar taxas de retorno 
supernormais conhecidas no período atual. Toda a informação disponível já está incorporada no preço das ações.

A eficiência informacional pode ser definida de três formas distintas. O mercado pode ser considerado eficiente na forma fraca se promover um ajuste lento e gradual nos preços, após a divulgação de uma informação relevante. Para o teste desta forma de eficiência, o conjunto de informações observado são os preços históricos das ações. Será considerado eficiente na forma semiforte, após o anúncio da informação, se o mercado conduzir os preços a novo patamar que, ainda não sendo o patamar de equilíbrio, não apresente grande volatilidade em relação a este. Nesse caso, a informação relevante é toda aquela publicamente disponível, como anúncios relacionados à empresa e outros eventos que possam afetar seus fluxos futuros de caixa. Finalmente, um mercado considerado eficiente na forma forte promove ajustes instantâneos nos preços, a partir de informações públicas e privadas.

A categorização relativa à hipótese de eficiência informacional foi formalizada inicialmente por Fama (1970), sendo posteriormente revista em Fama (1991), quando reclassificou o teste de eficiência fraca como teste de previsão de retornos e o estudo da eficiência semiforte como estudo de eventos ou estudo de anúncios.

Segundo Fama (1970), antes de se realizarem testes de eficiência, algumas condições de mercado devem ser observadas. Primeiro, deve-se certificar que todos os participantes reconheçam a importância da informação corrente sobre o preço atual e sobre a distribuição dos preços futuros de cada ação. Segundo, que o custo da transação acrescido do custo da informação seja zero. Dado que na prática tal fato não ocorre, uma condição mais realista é que o custo marginal da transação, somado ao da informação, não exceda o lucro marginal gerado por essa transação, e pela posse da informação: a relação custo/benefício nestas condições deve estar contida no intervalo $[0,1]$.

Diante das dificuldades empíricas de se trabalhar com premissas dessa natureza, Fama (1970) ressalta que tais condições são suficientes, mas não necessárias, para que a hipótese de eficiência de mercado se verifique. Para o autor, mesmo altos custos de transação não implicam, necessariamente, o não ajustamento de preços, dada a informação disponível. O mercado também pode ser eficiente, se um número suficiente de investidores (e não todos) tiver acesso à informação.

Algumas premissas, porém, são fundamentais para o estudo da eficiência informacional e estão relacionadas ao processo de formação de preços. A primeira delas estabelece que os retornos esperados ou preços de equilíbrio deverão ser um fair game, ou seja, definido o conjunto de informações relevantes, a expec- 
tativa de retorno deve ser função do risco inerente à ação. Essa premissa exclui a possibilidade de retornos excedentes ao retorno de equilíbrio, baseados apenas na informação contida no conjunto relevante, que não sejam consistentes com o risco da ação. A segunda premissa estabelece que os preços deverão ser linearmente independentes, ou seja, terão correlação serial igual a zero. Tal fato permitirá a afirmação de que o processo de formação de preços obedecerá a um modelo randômico ou aleatório (random walk).

Essas duas premissas garantem que a seqüência dos retornos passados não terá conseqüências sobre a distribuição de retornos futuros, o que não é o mesmo que afirmar que a informação passada tem valor nulo na formação desses retornos. Pode-se afirmar ainda que a hipótese de eficiência informacional pressupõe que os retornos observados não irão obedecer a nenhum padrão de regularidade ou, de forma equivalente, não apresentarão anomalias.

Anomalias são padrões de comportamento dos retornos que não podem ser explicados pelas teorias de finanças (Dimson, 1988). As mais comuns, como efeito tamanho e efeito índice preço-lucro $(\mathrm{P} / \mathrm{L})$, contrariam a premissa de fair game, já que, de acordo com elas, o retorno esperado das ações de empresas de pequeno porte e com baixo $\mathrm{P} / \mathrm{L}$ será maior que o retorno previsto por modelos que levem em conta o risco da ação, como o capital asset pricing model (CAPM). Já as anomalias relacionadas ao calendário contrariam a premissa de comportamento aleatório, por defenderem a existência de correlação entre os retornos passados e os retornos futuros das ações (Lemos e Costa Jr., 1995).

Uma última consideração acerca de mercados eficientes deve abordar a questão da racionalidade do mercado. Os conceitos de eficiência e racionalidade guardam estreita relação, não sendo, entretanto, idênticos. Segundo Elton e Gruber (1995), um mercado é ineficiente quando, baseado em alguma anomalia ou imperfeição na formação de preços, o investidor obtém retorno em excesso, após descontados os custos de transação. Para ser considerado irracional, entretanto, basta que tal anomalia ou imperfeição seja detectada. No entanto, seja num mercado racional, seja num mercado eficiente, se existirem diferenças entre o preço de uma ação e o valor desta ação, baseado no valor presente dos fluxos de caixa da empresa destinados ao investidor, esses desvios deverão ser aleatórios e rapidamente corrigidos. São evidências de irracionalidade a volatilidade no preço da ação que não é acompanhada por uma volatilidade semelhante nas variáveis fundamentalistas relacionadas a essa ação, quebras ocorridas no mercado e o efeito de sobre-reação, segundo o qual movimentos extremos nos preços das ações são seguidos por movimentos em sentido contrário, indicando que o mercado não soube avaliar corretamente uma informação. 


\section{Metodologia}

\section{O Mercado Brasileiro}

Como proxy para o mercado acionário brasileiro foi escolhido o índice divulgado pela Bolsa de Valores de São Paulo (IBOVESPA). De acordo com Leite e Sanvicente (1994), o valor absoluto deste índice corresponde ao valor monetário de uma carteira selecionada de ações negociadas naquela bolsa em determinada data. Sua variação é, portanto, a taxa de retorno que seria auferida pelo investidor que mantivesse essa carteira de ações durante o período.

De acordo com o Relatório Anual da Comissão Nacional de Bolsas de Valores para 1997, a Bolsa de Valores de São Paulo (BOVESPA) é responsável por cerca de $94 \%$ dos negócios realizados diariamente no mercado acionário brasileiro; portanto o IBOVESPA fornece uma boa representação do comportamento deste mercado. Ainda assim, uma das maiores críticas à representatividade deste índice diz respeito ao critério de seleção de sua carteira teórica, sendo o único no mundo a adotar a negociabilidade como critério de seleção, exclusão e ponderação de ações em sua formação (Leite e Sanvicente, 1994). Participam da carteira teórica as ações de maior negociabilidade nos últimos 12 meses e que, em conjunto, representem pelo menos $80 \%$ da soma dos índices de negociabilidade apurados para todas as ações negociadas à vista nos pregões deste período na BOVESPA. Adicionalmente, exige-se que cada ação selecionada por este critério tenha participado de pelo menos $80 \%$ dos pregões realizados no período considerado e que seu volume de negócios em reais (R\$) no período corresponda a mais do que $0,1 \%$ do volume total (em $\mathrm{R} \$$ ) de negociação no mercado à vista da BOVESPA no mesmo período.

Portanto a carteira é ponderada pela negociabilidade das ações componentes. A conseqüência disso é que o índice reflete eventuais concentrações no mercado; porém tal concentração não é uma falha metodológica. Ainda de acordo com Leite e Sanvicente (1994), essa concentração decorre da representatividade do índice: a carteira fica concentrada porque o índice reflete um mercado concentrado. Espera-se até que, a partir do segundo trimestre do ano 2000, com a retirada dos recibos da TELEBRÁS (RCTB) da carteira teórica, o índice possa adequar-se ao processo de desconcentração do mercado brasileiro. Como é a faixa do mercado de ações integrantes da carteira que é fixada em $80 \%$ da negociabilidade acumulada, um maior número de ações seria selecionado, se a concentração desse mercado fosse menor. 
Adicionalmente, a consideração do índice não implica perda de continuidade nas atualizações quadrimestrais da carteira teórica, uma vez que, pela sua metodologia, não pode haver investimentos adicionais na carteira, apenas a reinversão dos rendimentos proporcionados pelas ações componentes. Dessa forma, os proventos recebidos pelas ações componentes da carteira são nela reinvestidos, expandindo-se as respectivas quantidades teóricas das ações geradoras desses proventos; portanto o índice é um indicador do retorno total, pois abrange não apenas as variações das cotações das ações componentes da carteira, mas também o rendimento proporcionado pelos dividendos e direitos à subscrição por elas distribuídos. Por outro lado, em decorrência desse fator, ajustes por proventos tais como dividendos, bonificações e splits (desdobramentos) - garantem que apenas flutuações das cotações decorrentes de variação na oferta e procura das ações afetarão o valor do índice (Leite e Sanvicente, 1994).

Tomando-se por base tais constatações e para os fins do presente trabalho, o retorno diário do IBOVESPA, corrigido para proventos de acordo com o Banco de Dados da Economática, foi utilizado como benchmark para o retorno diário do mercado brasileiro.

\section{Mensuração dos Retornos Diários Normais e Anormais no Mercado Brasileiro}

De acordo com a sistemática de um estudo de eventos, para observar o ajuste promovido pelo mercado a partir de alguma informação relevante, deve-se gerar um retorno normal, retorno de controle, que seria obtido, se o evento não tivesse ocorrido (Kloeckner, 1995).

Em concordância com a elaboração de Brown e Warner $(1980,1985)$ de modelos gerais para mensuração de retornos anormais em estudos de eventos, este trabalho fez uso do modelo de retorno ajustado à média. Tal modelo estabelece que o retorno normal deve ser igual à uma constante $\mathrm{K}_{\mathrm{c}}$ que, neste caso, foi arbitrada como sendo a média diária dos retornos do IBOVESPA, em moeda local e ajustados por proventos, no período compreendido entre 01 de julho de 1996 e 01 de julho de 1997, período isento de choques de natureza externa e interna. A escolha deste período procurou satisfazer a condição de independência entre os períodos de observação e de estimação necessária aos estudos de evento, conforme exposto nos trabalhos de Brown e Warner (1985) e de Campbell e Mackinlay (1997). Dessa forma, o retorno diário anormal do mercado $\left(\mathrm{RA}_{\mathrm{it}}\right)$, por essa metodologia, é a diferença entre o retorno diário observado do IBOVESPA $\left(\mathrm{R}_{\mathrm{it}}\right)$ e sua média $\left(\mathrm{K}_{\mathrm{c}}\right)$ e, nesse trabalho, será observado num período total de 40 dias ao redor da data zero dos quatro eventos selecionados: (1) a crise asiática de outubro de 1997; (2) a crise russa em agosto de 1998; (3) o acordo do 
Fernanda F. Cordeiro Perobelli, Fernando S. Perobelli e Marcelo Aarestrup Arbex

Brasil com o Fundo Monetário Internacional em novembro de 1998 e (4) a mudança do regime cambial de janeiro de 1999. Matematicamente:

$$
\mathrm{RA}_{\mathrm{it}}=\mathrm{R}_{\mathrm{it}}-\mathrm{K}_{\mathrm{c}}
$$

\section{Descriçăo dos Períodos Selecionados para Análise}

No período de setembro de 1997 a janeiro de 1999, enfatizando os meses de outubro de 1997 (crise asiática), agosto de 1998 (crise russa), novembro de 1998 (pacote do FMI) e janeiro de 1999 (mudança no regime cambial), identifica-se que a formulação e condução da política econômica teve como objetivo principal a estabilização de preços. Nesse sentido, o policymaker compromete-se com uma regra de política que estabelece a manutenção das taxas de inflação em patamares reduzidos. Para tanto, o Governo utilizou-se de política monetária altamente restritiva, associada a uma regra de não desvalorizações cambiais.

A eclosão da crise asiática criou uma expectativa de instabilidade no mercado financeiro internacional, que se refletiu no aumento do risco associado aos investimentos nas economias emergentes (BACEN, 1998a). A conjuntura da economia brasileira, no momento da crise, caracterizava-se por uma trajetória ascendente da atividade produtiva, redução das taxas de inflação e tendência de estabilização do déficit comercial.

Com o intuito de diminuir as especulações sobre o impacto da crise sobre a economia brasileira e evitar um ataque especulativo mais severo ao real, o Banco Central dobrou as taxas de juros básicos (Selic), passando de $22 \%$ em setembro de 1997 para 42,2\% em outubro de 1997. Esta política, aliada à manutenção da política cambial, possibilitou a reversão das expectativas, retornando à normalidade o mercado de câmbio (BACEN, 1998b).

Esse período de turbulência levou a uma redução das reservas da ordem de US $\$ 8,2$ bilhões entre setembro e outubro de 1997. Este comportamento foi revertido em novembro de 1997, devido, em parte, às medidas que objetivavam captação de recursos externos e à própria percepção, por parte dos agentes econômicos, que os efeitos da crise tinham caráter transitório. As reservas estabilizam-se em US\$52 bilhões em novembro de 1997.

Mesmo diante de situações adversas, observava-se o comprometimento da autoridade monetária com a regra de política adotada. Esta idéia é fortalecida pela adoção das seguintes medidas: alta dos juros, atuação direta do Banco Central no sentido de captar reservas, medidas fiscais (Pacote 51), leilões cambiais de venda de divisas, entre outras (BACEN, 1998). 
O segundo episódio que afetou a economia brasileira foi a crise internacional acarretada pela moratória russa e reestruturação de sua dívida interna. Cabe ressaltar que a instabilidade internacional fez com que organismos internacionais discutissem uma intervenção de forma coordenada, a fim de diminuir os efeitos da crise sobre os países emergentes e desenvolvidos (IPEA, 1998a).

Diante deste cenário, o Governo brasileiro enfrentou a crise com o comprometimento de manutenção das regras anteriormente estabelecidas, ou seja, a estabilização de preços. Para tal, conduziu a política monetária por meio de um aumento da taxa de assistência financeira (TBAN), suspendeu temporariamente a taxa básica (TBC) como referência para as operações de assistência financeira de liquidez, redefiniu regras relativas ao recebimento do compulsório e conduziu o monitoramento da Selic mediante operação primária e secundária no mercado aberto, o que levou a taxa Over/Selic de $33,5 \%$ para $39,3 \%$ no período de setembro a outubro de 1998 (BACEN, 1998c). Cabe salientar que esse choque externo afetou a economia brasileira no seu âmbito interno, notadamente na perda de reservas cambiais e no aumento do déficit nominal; entretanto, mesmo em condições adversas, a autoridade monetária, a exemplo da crise asiática, manteve seu compromisso com a estabilização, tomando para tanto medidas apropriadas, além de defender o regime de bandas cambiais.

Em novembro de 1998, o país fechou um acordo com o Fundo Monetário Internacional, com o objetivo de garantir a consistência temporal da política econômica, assim como fortalecer a credibilidade do Brasil perante o mercado internacional. $\mathrm{O}$ acordo fortalecia a idéia de manutenção das regras vigentes. Entre as principais medidas destacam-se a geração de superávits comerciais, diminuição gradativa das despesas com juros da dívida, equilíbrio das contas públicas, aprovação de reformas estruturais, entre outras (IPEA, 1998b).

Entretanto, desde o segundo semestre de 1997, fortes eram as pressões sobre as reservas cambiais brasileiras. No final de 1998, a excessiva fuga de capitais verificada, apesar das elevadas taxas de juros oferecidas pelos papéis brasileiros, levou os agentes econômicos a suspeitarem da capacidade das autoridades monetárias na defesa da banda cambial. Essas pressões intensificaram-se no início de 1999, de tal forma que, em 13 de janeiro de 1999, o Banco Central cedeu às pressões e ampliou a banda cambial, aumentando as intervenções tanto no mercado à vista quanto no mercado futuro; contudo a ampliação da banda cambial não proporcionou os efeitos esperados sobre as reservas, levando o Banco Central, em 15 de janeiro de 1999, a flexibilizar a política cambial mediante a adoção do regime flutuante. A taxa de câmbio média para janeiro foi de $\mathrm{R} \$ 1,52 /$ US\$ e para fevereiro de R \$1,91/US\$ (Campelo Jr., 1999). 


\section{Hipóteses e Testes Empíricos}

Com o objetivo de avaliar se o mercado promoveu ajustes nos preços, nos choques tanto de origem externa quanto interna, foram calculados os retornos diários anormais ao redor das quatro datas selecionadas em períodos alternativos de 20 dias anteriores e 21 dias posteriores (incluindo a data zero), 10 anteriores e 11 posteriores, 7 anteriores e 8 posteriores, 5 anteriores e 6 posteriores e 3 anteriores e 4 posteriores. Cabe ressaltar que o procedimento utilizado para a determinação pontual das datas dos eventos se deu da seguinte forma: (1) para os dois primeiros eventos, tomou-se como base o comportamento do dólar via taxa média do Banco Central (Ptax); (2) no que tange ao acordo com o FMI, a data escolhida foi a de entrega do memorando de intenções e (3) quanto à flexibilização do câmbio, a data considerada foi o dia 15 de janeiro de 1999, quando a autoridade monetária efetivamente abandonou o regime de bandas cambiais. As hipóteses testadas para cada período foram:

$\mathrm{H}_{0}$ : os retornos anormais diários no período anterior à data do ajuste da política são iguais aos retornos anormais no período posterior, incluindo a data zero;

$\mathrm{H}_{\mathrm{a}}$ : os retornos diários anormais nos dois períodos são diferentes.

Procedeu-se ao teste de somatório de postos de Wilcoxon. Segundo Sincich (1996), o somatório das classificações dadas aos retornos diários anormais anteriores e posteriores (T1 e T2) serão estatisticamente próximos, se as duas distribuições de retornos forem iguais e T1 será maior (menor) que T2, se D1 for deslocada para a direita (esquerda) de D2.

Neste trabalho, a estatística de teste utilizada foi o somatório de postos T1, dado que o número de dias observados antes do evento $\left(\mathrm{n}_{1}\right)$ era inferior ao número de dias após o evento, incluindo a data zero $\left(\mathrm{n}_{2}\right)$.

\section{Resultados e Conclusóes}

Pelo teste de Wilcoxon, cujo resultado se encontra no Quadro 1, pode-se verificar que os retornos anormais diários não são estatisticamente diferentes nos períodos caracterizados como crise asiática e moratória russa e na data de divulgação do acordo com o FMI, ou seja, não houve nenhuma modificação brusca do mercado diante destes eventos. Já em relação à mudança cambial, os retornos ex-ante e ex-post mostram-se estatisticamente diferentes em todos os períodos de análise. 
Expectativas Racionais e Eficiência Informacional

\section{Quadro 1: Resultado do Teste de Somatório de Postos de Wilcoxon}

\begin{tabular}{|c|c|c|c|c|c|c|}
\hline \multicolumn{7}{|c|}{ Resumo dos resultados } \\
\hline Período & $\begin{array}{l}\text { Estatística de } \\
\text { teste }\end{array}$ & $\mathbf{T}$ & $\begin{array}{c}\text { Crise } \\
\text { asiática }\end{array}$ & $\begin{array}{l}\text { Crise } \\
\text { russa }\end{array}$ & $\begin{array}{c}\text { Acordo } \\
\text { FMI }\end{array}$ & $\begin{array}{l}\text { Mudança } \\
\text { cambial }\end{array}$ \\
\hline 20 anteriores & \multirow{2}{*}{$\begin{array}{l}\mathrm{T} 1 \\
(\mathrm{n} 1<\mathrm{n} 2)\end{array}$} & $\mathrm{T} 1$ & $404^{*}$ & $435^{*}$ & $424 *$ & $334+$ \\
\hline 21 posteriores & & $\mathrm{T} 2$ & 457 & 426 & 437 & 527 \\
\hline 10 anteriores & \multirow{2}{*}{$\begin{array}{l}\mathrm{T} 1 \\
(\mathrm{n} 1<\mathrm{n} 2)\end{array}$} & $\mathrm{T} 1$ & $107^{*}$ & $105^{*}$ & $106^{*}$ & $71+$ \\
\hline 11 posteriores & & $\mathrm{T} 2$ & 124 & 126 & 125 & 160 \\
\hline 7 anteriores & \multirow{2}{*}{$\begin{array}{l}\mathrm{T} 1 \\
(\mathrm{n} 1<\mathrm{n} 2)\end{array}$} & $\mathrm{T} 1$ & $50 *$ & $58 *$ & $50 *$ & $32+$ \\
\hline 8 posteriores & & $\mathrm{T} 2$ & 70 & 62 & 70 & 88 \\
\hline 5 anteriores & \multirow{2}{*}{$\begin{array}{l}\mathrm{T} 1 \\
(\mathrm{n} 1<\mathrm{n} 2)\end{array}$} & $\mathrm{T} 1$ & $23 *$ & $30 *$ & $31^{*}$ & $16+$ \\
\hline 6 posteriores & & $\mathrm{T} 2$ & 43 & 36 & 35 & 50 \\
\hline 3 anteriores & \multirow{2}{*}{$\begin{array}{l}\mathrm{T} 1 \\
(\mathrm{n} 1<\mathrm{n} 2)\end{array}$} & $\mathrm{T} 1$ & 9* & $15^{*}$ & $14^{*}$ & $6+$ \\
\hline 4 posteriores & & $\mathrm{T} 2$ & 19 & 13 & 14 & 22 \\
\hline
\end{tabular}

Fonte: elaboração própria a partir dos dados da Economática.

Os resultados apresentados no Quadro 1 também podem ser verificados pela análise do Gráfico 1.

\section{Gráfico 1: Comportamento do IBOVESPA em Períodos de Crise}

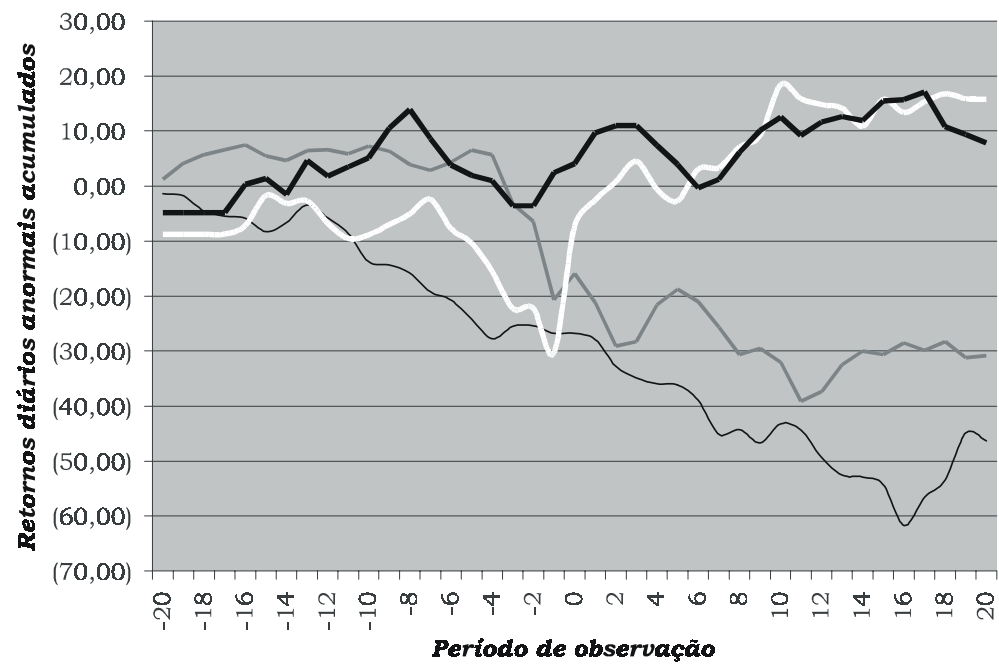

Crise asiätica - Crise russa $\quad$ Mudança cambial - Acordo FMI

Fonte: elaboração própria a partir dos dados da Economática. 
Os resultados obtidos via retornos diários anormais acumulados são condizentes com a proposição de racionalidade dos agentes participantes do mercado de ações brasileiro. A hipótese de expectativas racionais, corroborada pela de eficiência informacional, postula que as variáveis futuras refletem toda a informação publicamente disponível e mudanças nas variáveis correntes e futuras através do tempo são decorrência exclusiva de mudanças não-antecipadas pelos agentes. Acrescenta-se ainda que somente informações correntes novas, que não puderam ser previstas anteriormente, podem levar os negociadores de um mercado eficiente a mudarem seus planos.

Dos quatro eventos selecionados, é possível identificar um padrão relativamente semelhante de comportamento para os retornos do IBOVESPA nos episódios da crise asiática, crise russa e acordo com o FMI. Pelo Gráfico 1, observa-se que os retornos diários anormais acumulados ao redor dessas três datas não sofreram alterações bruscas no intervalo de tempo selecionado para análise, num total de 20 dias anteriores e 21 dias posteriores ao evento.

Contudo a mudança cambial, promovida pelo Banco Central em janeiro de 1999, afetou significativamente os retornos diários anormais do IBOVESPA. Pelo Quadro 1 e pelo Gráfico 1, é possível identificar dois comportamentos distintos desses retornos no período anterior e posterior à alteração do regime cambial. Nos 21 dias após a flexibilização do câmbio, os retornos apresentam uma trajetória ascendente, diferentemente dos 20 dias anteriores, quando se observa uma trajetória mais regular.

A partir dessas observações, pode-se concluir que, nos períodos caracterizados pelas crises asiática e russa, as medidas restritivas adotadas pelo Governo, materializadas principalmente pela elevação dos juros domésticos, visavam à preservação dos fluxos de capitais externos e, conseqüentemente, do nível de reservas cambiais. A adoção de tais medidas reforçava, junto ao mercado, o compromisso com a manutenção das regras.

Com relação ao acordo brasileiro com o FMI, era patente que, para a manutenção do regime de bandas cambiais, o país necessitaria de um aporte de recursos por parte de organismos internacionais que viabilizasse o equilíbrio do balanço de pagamentos e resgatasse a credibilidade do país junto à comunidade financeira internacional. Diante do compromisso do Governo de não desvalorizar discricionariamente o real, os agentes também avaliaram corretamente o acordo com o FMI, o qual foi acrescentado ao conjunto de informações como uma medida de contingência, e não de socorro, ao Brasil. Essa observação é corroborada pelo Gráfico 1, em que se nota que os retornos apresentam um trajetória sem grandes oscilações. 
Em relação à mudança cambial, amparando-se na hipótese de expectativas racionais, é possível afirmar que os agentes não anteciparam esse evento, o qual caracterizaria um choque aleatório não incorporado ao conjunto de informações dos agentes. À luz da hipótese de eficiência informacional, pode-se afirmar que se tratava de uma informação não prevista e, portanto, ainda não precificada. Tais afirmações podem ser corroboradas pela seguinte percepção de um player atuante no mercado:

“[...] desde a crise da Rússia vínhamos chamando a atenção para a insustentabilidade da política cambial, a proximidade de uma livre flutuação da taxa de câmbio e o provável sucesso desta mudança em termos de manutenção dos baixos patamares de inflação e recuperação das expectativas positivas para [a] economia, dados fatores já existentes como a prática de elevadas taxas de juros desde a crise da Ásia, a recessão da economia, a ausência de mecanismos de indexação de preços e salários e os grandes avanços em termos de produtividade e dinamismo de nossa economia nos últimos anos. No entanto, na entrada do ano os mercados não precificavam corretamente este cenário de ruptura e rápida recuperação" (Banco Liberal, 1999).

Esse comportamento é compreensível na medida em que havia, naquele momento, a confiança do público na manutenção das bandas cambiais, tendo em vista o comportamento das autoridades econômicas brasileiras nos episódios da crise asiática e russa e o acordo com o FMI. Cabe salientar que era crescente também a percepção do público quanto à incapacidade do Governo em manter seu compromisso, qual seja, a defesa da banda cambial e a manutenção da regra de não-desvalorizações. Diante de uma situação adversa de fuga de capitais externos e taxas de juros elevadas, o Governo optou por abandonar a regra, perdendo, com isso, credibilidade junto aos agentes internos e externos. Esse fato novo ou evento surpresa gerou uma mudança na tendência verificada no mercado acionário brasileiro, como pode ser verificado no Gráfico 1.

Em síntese, observou-se que o comportamento da autoridade monetária em face da crise asiática e da crise russa e o próprio acordo com o FMI foram devidamente avaliados pelos agentes econômicos como sendo medidas que fortaleciam o comprometimento do Governo com as políticas anteriormente anunciadas, não gerando por isso alterações bruscas nos retornos diários do IBOVESPA. Por sua vez, a mudança cambial caracterizou-se numa surpresa ou choque aleatório para o público, na medida em que se materializou no abandono da regra de política econômica repetidamente anunciada e defendida pelo Governo em episódios passados. Pode-se afirmar, portanto, que o mercado de capitais brasileiro se mostrou eficiente, em sua forma semiforte, em relação à condução de política 
econômica num cenário de regras. Já em relação à avaliação da eficiência na forma forte, a mesma afirmação não seria viável, dado que a percepção de, pelo menos, um participante do mercado não foi amplamente compartilhada pelos demais e, portanto, incorporada aos preços das ações.

\section{NotAS}

${ }^{1}$ Variações antecipadas em políticas fiscal e monetária não causam efeito algum em variáveis reais, como taxa de desemprego e produto real. Esta conclusão é chamada, pela economia novoclássica, de Proposição de Ineficácia das Políticas. Essa proposição de ineficácia já pressupõe por sua vez a desejabilidade de se conduzir a política econômica por meio de regras de política de feedback.

${ }^{2}$ Para uma resenha detalhada sobre a literatura de inconsistência temporal e credibilidade, ver Arbex, Almeida e Fontes (1997).

${ }^{3} \mathrm{Se} \delta$ assume um valor próximo a zero, o que normalmente ocorre para dados diários ou semanais, a equação (2) é um passeio aleatório. Se os agentes econômicos são racionais e esperam que a taxa de retorno presente permaneça constante, então não é possível estabelecer alguma regra de negociação que utilize informações passadas para obter lucros supernormais.

\section{ReFERÉNCIAS BiblográficAs}

ARBEX, M. A.;

ALMEIDA;

FONTES.

Inflação e credibilidade : uma resenha. In: FONTES, R. Estabilização e crescimento. Viçosa : Editora da UFV, 1997.

BACCHI, M. R. P.

Integração, co-integração e modelo de correção de erro : uma introdução. Viçosa, 1995. (mimeo).
BACEN.

Boletim do Banco Central do Brasil. jan. 1998a.

Boletim do Banco Central do Brasil. fev. 1998b.

Boletim do Banco Central do

Brasil. mar. 1998c.

BANCO LIBERAL.

Carta do administrador. jun. 1999. 
BARBOSA, E. S.

Uma exposição introdutória na macroeconomia novo-clássica. In: FALCÃO, M. L. (Org.). Moeda e produção : teoria comparada. Brasília : Editora da UnB, 1992. p. 233-284.

BEGG, D. K. H.

The rational expectations revolution in macroeconomics: theories \& evidence. [S.1.] : The John Hopkins University Press, 1982.

BEKAERT, G. et al.

O papel dos mercados de capitais no crescimento econômico. Chicago : Catalyst Institute, 1995.

BROWN, S. J.;

WARNER, J. B.

Measuring security price performance. Journal of Financial Economics, v. 8, n. 3, p. 205-258, Sept. 1980.

Using daily stocks returns : the case of event studies. Journal of Financial Economics, v. 14, n. 4, Mar. 1985.

BUITER, W.

The macroeconomics of Dr. Pangloss : a critical survey of the new classical macroeconomics. The Economic Journal, Mar. 1980.
CALVO, G. A.

On the time consistency of optimal policy in a monetary economy. Econometrica, v. 46, n. 6, p. 411-428, 1978.

CAMPBELL, J.;

MACKINLAY, A.

The econometrics of financial markets. [S.1.] : Princeton University Press, 1997.

CAMPELO JR.

A hora da queda? Revista Conjuntura Econômica, abr. 1999.

DEWBRE, J. H.

Interrelationships between spot and futures markets : some implications of rational expectations. American Journal of Agricultural Economics, v. 63, p. 925-933, Dec. 1981.

DIMSON, E.

Stock market anomalies. [S.1.]: Cambrigde University Press, 1988.

ELTON, E. J.;

GRUBER, M. J.

Modern portfolio theory and investment analysis. 5. ed. New York : John Wiley \& Sons, 1995. 
FAMA, E.

Efficient capital markets : a review of theory and empirical work. The Journal of Finance, v. 25 , n. 2, p. 383-417, Mar. 1970.

Efficient capital markets II. The Journal of Finance, v. 46, n. 5, Dec. 1991.

FISHER, S.

Long-term contracts, rational expectations and the optimal money supply rule. Journal of Political Economy, Feb. 1977.

IPEA.

Carta de conjuntura. n. 82, set. 1998a.

Carta de conjuntura. n. 83, dez. 1998b.

KANTOR, B.

Rational expectations and economic thought. Journal of Economic Literature, v. 17, p. 1422-1447, Dec. 1979.

\section{KLOECKNER, G. O.}

Estudos de evento : a análise de um método. Revista Brasileira de Administração Contemporânea, v. 1, n. 2, p. 262-270, set. 1995.
KYDLAND, F. E.;

PRESCOTT, E. C.

Rules rather than discretion : the inconsistency of optimal plans. Journal of Political Economy, v. 85, n. 3, p. 473-491, 1977.

LEITE, H. P.;

SANVICENTE, A. Z.

Índice Bovespa : um padrão para os investimentos brasileiros. São Paulo : Atlas, 1994.

LEMOS, M. O.;

COSTA JR., N. C. A.

O efeito de sobre-reação no curto prazo no mercado de capitais brasileiro. Revista Brasileira de Administração Contemporânea, v. 1, n. 2, p. 292-309, set. 1995.

LUCAS JR., R. E.;

SARGENT, $\mathrm{T}$.

After Keynesian macroeconomics. In: MILLER, P. J. (Org.). The rational expectations revolution: readings from the front line. [S.1.]: Massachusetts Institute of Technology, 1996. p. 05-30.

MARKOWITZ, H.

Portfolio selection : efficient diversification of investiment. New York : John Wiley \& Sons, 1959. 
MUTH, J. F.

Rational expectations and the theory of price movements. In: HOOVER, K. D. (Org). The new classical macroeconomics. Cambridge University Press, 1992. 1. v., p. 03-23.

PERSSON, T.;

TABELLINI, G.

Macroeconomic policy, credibility and politics. Paris : Harwood Academic Publishers, 1996.

SARGENT, T. J.;

WALLACE, N.

Rational expectations and the theory of economic policy. In: HOOVER, K. D. (Org). The new classical macroeconomics. [S.1.]: Cambridge University Press, 1992. 1. v., p. 275-289.

SILVA JR., G. E.

Aspectos do desenvolvimento da controvérsia do debate regras versus discrição em política monetária. Economia Rural, n. 4, p. 06-10, out./dez. 1996.

SINCICH, T.

Business statistics by example. 5. ed. Englewood Cliffs, NJ : Prentice-Hall, 1996. 